\title{
OVERCOMING THE CHALLENGES OF GLOBAL COLLABORATION THROUGH DESIGN EDUCATION
}

\author{
Ross BRISCO ${ }^{1}$, Robert lan WHITFIELD ${ }^{1}$, Hilary GRIERSON ${ }^{1}$ and Erik BOHEMIA ${ }^{2}$ \\ ${ }^{1}$ Design, Manufacture and Engineering Management, University of Strathclyde \\ ${ }^{2}$ Academy for Design Innovation Management
}

\begin{abstract}
The challenges of integrating technology in global design classes have been published in the literature, but it is unclear if this knowledge makes its way back to the classroom. This paper investigates knowledge transfer by documenting the results of four workshops across two institutions and two distributed design classes. Participants were asked to identify the challenges of distributed design, the functionality of technologies to overcome the challenges and guidance on how best to perform distributed design to best help future students. 17 challenges, 10 functionalities and 8 guidelines were developed. The identification of challenges, functionalities and subsequent guidance created can be utilised to assist future students and educators of distributed design. Analysis of gaps in the knowledge identify where theories have not been transferred from literature to the classroom and will help to identify how best to fill the gaps in knowledge. The workshops also present a novel way to engage students in analysing their own collaborative work practices.
\end{abstract}

Keywords: Global design, distributed collaboration, online teamwork, project-based learning

\section{INTRODUCTION}

As technologies evolve students expect to be able to utilise the same functionality they use for personal and social communication for their academic and professional communication. This intent has been demonstrated in several group based design classes as reported by [1], [2], and [3]. To support students in their understanding of the benefits of global collaboration and practical implementation of good practices, educators must ensure that they are able to offer meaningful and realistic opportunities to experience real-world design scenarios. In a distributed setting, collaboration is supported by technologies which students should experience to build their skills in digital literacy [4]. Therefore, educators have a responsibility to ensure where available that state-of-the-art practices are being imparted to students.

Collaborative design teams face many problems when it comes to tackling daily issues of communication, co-operation and co-ordination which all contribute towards successful collaboration [5]. There are many human factors which affect co-located teamwork focusing on how a team can work better together by building trust [6]. The addition of technology to support distributed design teams has enabled a more agile way of working but also brings technological factors which can have a detriment to the design process. If educators are more aware and able to covey the challenges inclusive of both human and technological factors to their students, the next generation of workers will be in a better position to adapt to a modern, agile and dynamic workplace [7]. Using project management software, communication technologies and data storage solutions, students have access to all the essential tools which professional design teams utilise [8].

The challenges of integrating technology in global design classes have been published in the literature [9]. This could be utilised by the wider design community to improve practices, but it is unclear if this knowledge makes its way back to the classroom across institutions and then is utilised to improve and iterate on current teaching practices. There are many situations within design education where this might be possible for project-based learning (PBL) classes such as classes in global design. One approach to achieve this is by utilising knowledge from the literature and from student experiences during global design workshop sessions and asking students to engage in critically analysing their own 
collaborative design practices. This is the approach taken in his research which focused on two global design modules hosted by two separate institutions.

\subsection{Teaching global design}

There are several example projects of where academics might teach students about the challenges of utilising collaborative technologies in their design education to help them make better decisions and build their own knowledge. This paper focuses on The Global Studio and the Global Design Project.

The Global Studio has been jointly organised between several international universities and commercial partners since 2007. The class delivers a mixture of project-based learning circumstances to students alongside taught classes on state-of-the-art theories of good global design. The class is unique in giving students the experience of having the position of both client and design team for a complete appreciation of the complexities of global collaborative design. In 2017 the project was jointly participated by Tecnun Universidad de Navarra (Spain), University of Applied Arts Vienna (Austria), Shibaura Institute of Technology (Japan), Suor Orsola Benincasa University of Naples (Italy), Middle East Technical University (Turkey), Unisinos Universidade do Vale do Rio dos Sinos (Brazil) and Loughborough University (England).

The Global Design Project has emerged from the DIDET project [10] and has been in its current form since 2006. The class employs joint lectures hosted by the participating institutions from multidisciplinary backgrounds. Each team acts as a distributed design group who all collaborate to design a product and deliver as a distributed presentation. In 2017 the project was participated by City University London (England), University of Malta (Malta) and University of Strathclyde (Scotland).

In the following sections, the outcomes of four workshops are reported to identify the challenges of distributed collaborative work, how the functionality of technology might overcome these challenges and guidance on best practices for student projects. The method of investigation is described in the methodology section including information on the workshop format. The results section reports the outcomes of the workshops and the links between them. The discussion section gives some examination of the results and the outcomes of this study towards future work.

\section{METHODOLOGY}

Four workshops were held over a two-year period with students experienced in global design. The workshops aimed to introduce the complexities of distributed design before asking students to critically analyse their own practices and create ways to overcome the challenges of distributed design. All workshops included an introduction to the field of distributed design to ensure all participants have a shared understanding of the topic. Workshop one took place at Loughborough University design school with 26 students of The Global Studio 2016. Workshop two took place at Strathclyde University with 18 students of The Global Design Project 2016. Workshop three took place with 26 students of The Global Design Project 2017. And workshop four took place with 28 students of The Global Studio 2017.

The workshops were formatted as follows: an introductory lecture on collaboration with a focus on the use of technology in a design education context, three workshop activities which asked students to answer questions on collaborative design and discuss within their teams, conclusions from literature and previous workshops.

Three questions were asked at each workshop: "What are the challenges of supporting collaboration during the design process?"; "Which functionality of collaborative design technologies can be used to overcome these challenges?"; and "Which guidelines would you create to inform future distributed design engineers?". Teams were formed of attendees to work on activities. Teams were typically between four and six participants. Teams were supplied with large format paper, marker pens and post-it notes (Figure 1) to complete the activities. Teams could display the knowledge in whichever way they felt was most appropriate e.g. lists, mind maps, post-it notes. During workshops, teams were asked to select their top three challenges to work on. Some teams utilised sticky dots to democratically select their top three challenges.

\section{RESULTS}

The following section details the outcomes of the workshops. After all workshops were completed the outcomes were collected together to give a holistic response to each question. Where teams developed the same answer to a question this was combined to narrow down the responses to a concise list. The 
outcomes are listed in response to their associated question in the order they were asked during workshops. Following the outcomes, an alluvial diagram is utilised to display how the challenges, functionality and guidance are related according to the participants of the workshops.

\subsection{Identifying the challenges}

The first question asked, "What are the challenges of supporting collaboration during the design process?". Teams generated a list of challenges to support collaboration during the design process based on their experiences and knowledge. 17 challenges were identified by students in total listed in Table 1. The majority are challenges experienced within the classroom, but some challenges went beyond the classroom setting as students brought their experience of industry design projects. The following is a description of the challenges identified during workshops:

Communicating requirements versus aspirations are required according to participants of the workshops when working with inexperienced designers or when dealing with overpowering team members and finding a balance between democracy versus a dictatorship. Students need to experience teamwork scenarios in distributed settings to get used to the sense of lack of control and to understand a need to build trust between team members.

Identifying capable tools was identified as important for student's teams as the vast amount of available technologies and functionality is difficult to navigate. It was suggested that students can overlook the need for technologies to enable project management and the part it plays in minimising miscommunications. Identifying capable tools also has a part to play in overcoming language barriers and awareness of cultural differences.

Healthy teamwork was identified as ensuring a cohesive supportive environment for teams to work. This involves many human factors such as managing team members personalities and encouraging motivation for the project. This is helped by team members being open and honest about their own personal motivations for a project by sharing their priorities.

It was identified by participants of the workshop that problems can arise from multidisciplinary teams who share similar but not complete knowledge with each other. This can lead to issues with the quality of work standards and expectations such as the need to share work between team members. In some cases, students went above the remit of understanding their own work and looked to future problems they might face in the workplace. Generational adoption of technology refers to the willingness of team members, especially the older generation to adopt modern functionality to achieve a design goal.

\subsection{Identifying functionality}

The second question of the workshop asked: "Which functionality of collaborative design technologies can be used to overcome these challenges?". Participants were asked to select their top three challenges from the previous question within their groups and to identify the functionality of technologies which might be able to overcome the challenges. Ten functionalities of technology were identified as listed in

Table 1 and linked were possible with the challenges. The following is a description of the functionality identified during workshops:

Messaging is a functionality offered by many technologies such as instant messengers, social network sites and e-mail. Messaging can be asynchronous when required to enable rapid communication and clarify information, or asynchronous when required to document a design process. Messaging can offer the ability to know if a message has been read which was identified as a method of improving social understanding between team members and can alleviate tension. In addition, messaging was identified as a method for encouraging all team members to contribute when communication breakdown occurs such as when team members do not feel confident to contribute face-to-face.

Voting is a functionality offered in several forms but commonly as a multiple-choice question. This functionality was identified as a method to democratically make decisions when a binary (yes / no) answer is required.

Video conferencing can offer teams the ability to have a face-to-face conversation in a distributed environment. Video conferencing can come in a range of forms from a professional setup space to a consumer mobile phone app. Having face-to-face time was identified as offering the ability for teams to 'break the ice' if they have not had the opportunity in a collocated setting and this can assist in building trust amongst team members. 
Profiles are a functionality commonly associated with social network sites. Profiles enable team members to share information about themselves and give an overview of their personalities. Greater social communication was recognised as a way of building trust amongst team members.

Networking was identified as a method for designers and the design team to expand their capabilities by expanding their resources. This can be associated with social networking or through e-mail gatekeepers who offer a connection to a required resource.

Collaborative document editing allows teams to work on documents at the same time, enabling all to have the opportunity to contribute. This functionality ensures documents are up to date in real time and there are no difficulties with outdated versions of documents. Shared documents were recognised as enabling project management techniques to be implemented by sharing management documents such as Gantt charts, and planning documents such as resource planners.

Electronic whiteboards can be utilised in design teams to share drawings live across locations. This functionality was identified as having the ability to enable collaborative drawings where sketches can be edited and updated by multiple team members and can be used for ideation tasks such as brainstorming.

Shared calendars are available on several platforms. It was acknowledged that team members could utilise this functionality to share their own calendar and can compare their own with their teams to select appropriate times for meetings or to ensure all are aware of upcoming deadlines.

Cloud storage was recognised as a technology to enable teams to store and access files in a shared location. All team members should have access to this location whenever required. Team members can utilise the cloud storage space to reflect on previous work.

Task lists were identified as a functionality as part of a team's project management plan to ensure all team members are aware of imminent tasks and the progress of ongoing tasks. This can be useful in scheduling work to be completed.

\subsection{Creating guidance}

The third and final question of the workshops asked: "Which guidelines would you create to inform future distributed design engineers?". Eight functionalities of technology were identified as listed in

Table 1 and linked were possible with the challenges and the functionalities. The following is a discussion of the guidance created during workshops:

When a team member asks a question in a global design project, ensuring prompt responses to questions addresses the problems of motivation and miscommunications. Participants of the workshops discussed how problems can arise or be made worse through long confusing messages and obscure meaning. It was proposed that prompt responses will encourage motivation which can be achieved through keeping communications simple, short, complete and directed towards the person who requires the information.

Infrequent communication was identified as an issue which links to the building of trust, clarification of problems, contribution of all team members and problems associated with awareness of work. Participants suggested that if these can be overcome, teams will ensure regular communication to minimise miscommunications and this will help to deal with overpowering team members. It was suggested during the workshops that scheduling regular meetings and communication between meetings will help to overcome these problems.

Group working is essential in collaborative design teams to ensure all knowledge is utilised. Participants of the workshops recognised the impact of ensuring group working in the building of trust between group members, in the decision-making process and in delivering real-time synchronous project updates. The building of trust can be supported by ensuring group working through the sharing of personal and information by building relationships between team members.

Problems may arise in teams relating to incomplete or improper procedures. Participants of the workshops identified that face-to-face meetings can be a solution to clarify issues and ensure healthy teamwork. It was suggested that protocols need to be developed within teams which are clear to all team members, agreed upon by all team members and enforced when they break down. In addition, it was suggested that to deal with overpowering team members who might enforce their views, the methods and approach must be discussed and agreed.

Participants of the workshops identified the lack of knowledge management techniques utilised by students who perhaps do not have access to software or who lack experience with these tools and methods. By enabling project management techniques, co-ordination and co-operation will benefit 
greatly and participants of the workshops suggested that the effectiveness and efficiency of the design process will also benefit.

Table 1. Output from workshops demonstrating the perceived link between challenge, functionality and guidelines identified and created by students.

\begin{tabular}{|c|c|c|}
\hline Challenge & Functionality & Guideline \\
\hline \multirow[t]{2}{*}{ Dealing with overpowering team members } & Video conferencing & Agree on team protocols \\
\hline & & Discuss and agree methods of design \\
\hline \multirow[t]{2}{*}{ Building trust } & Profiles & Ensure group working \\
\hline & Video conferencing & Ensure regular communication \\
\hline Encouraging motivation & Messaging & Ensure prompt responses \\
\hline Healthy teamwork & Video conferencing & Ensure regular communication \\
\hline Minimising miscommunications & Messaging & Ensure regular communication \\
\hline Democracy vs dictatorship & Voting & Ensure group working \\
\hline Enabling project management & collaborative document editing & Utilise knowledge management techniques \\
\hline Sharing priorities & collaborative document editing & Ensure group working \\
\hline Managing personalities & Profiles & \\
\hline \multicolumn{3}{|l|}{ Communicating requirements versus aspirations } \\
\hline \multicolumn{3}{|l|}{ Generational adoption of technology } \\
\hline \multicolumn{3}{|l|}{ Overcoming language barriers } \\
\hline \multicolumn{3}{|l|}{ Sharing physical prototypes } \\
\hline \multicolumn{3}{|l|}{ Access to software } \\
\hline \multicolumn{3}{|l|}{ Knowledge gaps caused by multidisciplinary } \\
\hline Quality of work standards & & \\
\hline \multirow{9}{*}{ No challenge identified } & & \\
\hline & Messaging & Ensure regular communication \\
\hline & Messaging & Keep communication methods simple \\
\hline & Collaborative document editing & Utilise real time synchronous work \\
\hline & Shared calendar & Ensure regular communication \\
\hline & Task lists & Ensure regular communication \\
\hline & Networking & \\
\hline & Electronic whiteboards & \\
\hline & Cloud storage & \\
\hline
\end{tabular}

\section{DISCUSSION}

The challenges identified by participants in the workshops can act as an indicator of student's knowledge in the education of the problems which might impact collaborative design education. Project-based learning is a well-established method of teaching which enables students to develop their 'soft skills' including collaboration. This is reliant on the student's willingness and drive to develop their own skills in these areas without much influence from teachings, such as issues associated with teamwork or any guidance on the best approaches. With the approach taken in this paper, students of The Global Studio and The Global Design Project have explored their own knowledge of distributed design problems and shared their knowledge with other students of the class. When asked to discuss the functionality of technologies which can be used to overcome the challenges in the workshop, students act as both the learners and the experts. Students apply their knowledge of software functionality with technologies that they are familiar with, to the challenges which were discussed before. This means that the software is always up to date and available to the students. If any new functionality or software becomes available students will have the opportunity to discuss how it might be implemented during the workshop and decide on its applicability. This can be useful in identifying technologies which are yet to be developed.

The final question asked students to create their own guidelines. This supports educational theories such as active learning [11] to involve the students in the analysis of the class and in self-evaluation. This encouraged students to take what they have learnt and apply it to their own teamwork. As the guidelines are decided and implemented by the students, they can apply it to the context of their class and team to ensure it is relevant to themselves. As guidelines were created in the same project teams, they acted as a formal agreement of how team members will act as they continue their projects.

After each workshop, a survey was conducted to elicit how beneficial students believed the workshop was for their education and in which ways they benefited, or the workshops could be improved. Students were very positive about the impact of the workshops on their education remarking that it allowed them to critically analyse how themselves and their teammates perform in the teams. This was beneficial for both The Global Studio and The Global Design Project students as they must produce a 
reflective report which the workshop helped to plan out how they will prepare with some discussion points. Not only are students encouraged to reflect on their collaborative requirements before the project, but they are asked to reflect after which supports educational theories of teaching and learning online [12]. Students began to show some critical thinking skills on how they and their team members approached the challenges and overcome some of these challenges before the end of the projects.

\section{CONCLUSIONS}

This paper documents the results of four workshops with students experienced in distributed design. These participants were asked to identify the challenges of distributed design, the functionality of technologies to overcome the challenges and guidance on how best to perform distributed design to best help future students. 17 challenges, 10 functionalities and 8 guidelines were developed. The identification of challenges, functionalities and subsequent guidance created can be utilised to assist future students and educators of distributed design. Analysis of gaps in the knowledge identify where theories have not been transferred from literature to the classroom and further studies with literature may help to identify what is missing and how best to fill the gaps in knowledge. In the future, it would be beneficial to improve how this knowledge is identified and delivered to students utilising the workshops as a delivery mechanism. The workshops also present a novel way to engage students in analysing their own collaborative work practices reflecting on their experiences and discussing how they might improve in a distributed design setting with the help of available technologies.

\section{ACKNOWLEDGEMENTS}

This work was supported by the EPSRC under Grant EP/M508159/1. Data from this study can be found at DOI: $10.15129 / 9647 \mathrm{~d} 268-c 35 a-4 c 6 e-a 325-c a a b b f 64 c 42 e$.

\section{REFERENCES}

[1] Hurn K. The Impact of Social Software in Product Design Higher Education. Design and Technology Education: An International Journal 2012, 17, p.35-48.

[2] Johri A., Teo H.J., Lo J., Dufour M. and Schram A. Millennial engineers: Digital media and information ecology of engineering students. Computers in Human Behaviour 2014, 33. p.286301.

[3] Lippert B., Ahrens M., Dekhiar J., Louhichi R., Song Y.-W., Toepfer F., et al. Integrated product development project in a multi-cultural and multi-professional background team: challenges and key success factors. DS 87-9 Proceedings of the 21st International Conference on Engineering Design (ICED 17) Vol 9: Design Education, Vancouver, Canada, 2017.

[4] Bohemia E. and Ghassan A. Globally Networked Collaborative Learning in Industrial Design. American Journal of Distance Education 2012, 26, p.110-25.

[5] Kock N. Encyclopaedia of E-collaboration. IGI Global; 2007.

[6] Morita P.P. and Burns C.M. Trust tokens in team development. Team Performance Management. 2014, 20, p.39-64.

[7] Gopsill J. A Social Media Approach to Support Engineering Design Communication. 2014.

[8] Mamo J., Farrugia P., Borg J., Wodehouse A., Grierson H. and Kovacevic A. Using engineering design tools in multidisciplinary distributed student teams. 17th International Conference on Engineering and Product Design Education, 2015, p. 99-104.

[9] Shen W., Barthès J.-P. and Luo J. Computer Supported Collaborative Design: Technologies, Systems, and Applications. Contemporary Issues in Systems Science and Engineering, John Wiley \& Sons, Inc. 2015, p. 537-73.

[10] Wodehouse A.J., Grierson H., Breslin C., Eris O., Ion W.J., Liefer L., et al. A Framework for Design Engineering Education in a Global Context. International Journal on Artificial Intelligence for Engineering Design, Analysis and Manufacture. 2010, 24, p.367-78.

[11] Prince M. Does Active Learning Work? A Review of the Research, Journal of Engineering Education. 2004, 93(3), p.223-231.

[12] Salmon G. E-moderating: The Key to Teaching and Learning Online, $4^{\text {th }}$ edition. London: Taylor \& Francis; 2000 p.132. 